\title{
Polyoxometalate coordinated transition metal complexes as catalysts: Oxidation of styrene to benzaldehyde/benzoic acid
}

\author{
SRINIVASA RAO AMANCHI ${ }^{\mathrm{a}}$, ANJALI PATEL ${ }^{\mathrm{b}}$ and SAMAR K DAS ${ }^{\mathrm{a}, *}$ \\ ${ }^{a}$ School of Chemistry, University of Hyderabad, Hyderabad 500 046, India \\ ${ }^{\mathrm{b}}$ Chemistry Department, Faculty of Science, M. S. University of Baroda, Vadodara 390 002, India \\ e-mail: skdsc@uohyd.ernet.in; samar439@gmail.com
}

MS received 16 January 2014; revised 5 April 2014; accepted 28 April 2014

\begin{abstract}
Oxidation of styrene is carried out by using heptamolybdate coordinated transition metal $\left(\mathrm{Co}^{2+}\right.$, $\mathrm{Zn}^{2+}$ ) complexes, $[2-\mathrm{ampH}]_{4}\left[\left\{\mathrm{Co}\left(\mathrm{H}_{2} \mathrm{O}\right)_{5}\right\} \mathrm{Mo}_{7} \mathrm{O}_{24}\right] \cdot 9 \mathrm{H}_{2} \mathrm{O}(\mathbf{1}),[3-\mathrm{ampH}]_{4}\left[\left\{\mathrm{Co}\left(\mathrm{H}_{2} \mathrm{O}\right)_{5}\right\} \mathrm{Mo}_{7} \mathrm{O}_{24}\right] \cdot 9 \mathrm{H}_{2} \mathrm{O}(\mathbf{2})$, [2$\mathrm{ampH}]_{4}\left[\left\{\mathrm{Zn}\left(\mathrm{H}_{2} \mathrm{O}\right)_{5}\right\} \mathrm{Mo}_{7} \mathrm{O}_{24}\right] \cdot 4 \mathrm{H}_{2} \mathrm{O}(3)$ and $[3-\mathrm{ampH}]_{4}\left[\left\{\mathrm{Zn}(3-\mathrm{ampy})\left(\mathrm{H}_{2} \mathrm{O}\right)_{4}\right\} \mathrm{Mo}_{7} \mathrm{O}_{24}\right] \cdot 4 \mathrm{H}_{2} \mathrm{O}(4)$ as catalysts and $\mathrm{H}_{2} \mathrm{O}_{2}$ as an oxidant at $80^{\circ} \mathrm{C}$. The leaching study has been carried out to check the quality of catalyst and it has been reused for three times with good percentage of conversion. For the first two catalysts (compounds 1 and 2), the major product obtained is benzaldehyde, and benzoic acid is the major product for next two catalysts (compounds 3 and 4). Stability of the catalysts has been analyzed by IR, UV-spectroscopy and powder X-ray crystallography.
\end{abstract}

Keywords. Heptamolybdate type polyoxometalate cluster anion; transition metal coordination complexes; oxidation of styrene; hydrogen peroxide as an oxidant; catalysis.

\section{Introduction}

Over the last few decades, the subject of polyoxometalates (POMs) is discussed in the areas of catalysis, ${ }^{1}$ materials science ${ }^{2}$ and medicinal chemistry. ${ }^{3}$ The redox properties of these POMs make them promising materials as good catalysts for a number of oxidation and dehydrogenation reactions of organic substrates. The main role of POM-cluster anion in catalysis is the activation of the oxidant, e.g., hydrogen peroxide, alkylhydroperoxide, etc. As a result of the activation of peroxide (oxidant), the inorganic peroxo, hydroperoxo, alkyl peroxo, acyl peroxo, etc., intermediates are formed, that are very reactive leading to the oxygenation of concerned organic substrate.

The oxidation of olefins to corresponding aldehydes or ketones is currently a fascinating process in industrial chemistry. This oxidation can be divided into three categories: (i) the cleavage of the $\mathrm{C}=\mathrm{C}$ bond by using the surface of the metal oxide, e.g., osmium or molybdenum oxides in stoichiometric amounts, ${ }^{4}$ (ii) the ozonolysis of olefin bond leading to the formation of keto-functional group ${ }^{5}$ and (iii) olefin oxidation by using hydrogen peroxide as an oxidant resulting in the formation of $\mathrm{C}=\mathrm{O}$ functional group directly. ${ }^{6}$ Some problems, associated with these oxidation reactions, are mainly wastage of the materials and usage of

\footnotetext{
*For correspondence
}

the highly expensive materials. Thus we have chosen hydrogen peroxide as a green oxidizing agent because, in this case, water is the side product, which is benign to our environment. And it is a very attractive oxidant for liquid phase reactions. ${ }^{7} \mathrm{H}_{2} \mathrm{O}_{2}$ can oxidize the organic compounds with an efficiency of $47 \%$ (active oxidant $=$ $47 \%)$ and it is very cheap $\left(<0.7 \mathrm{US} \$ \mathrm{Kg}^{-1}\right)$. It is essential to mention that $\mathrm{H}_{2} \mathrm{O}_{2}$ is an ideal and waste free oxidant if it is used without organic solvents and toxic materials. Safety reasons are not required very much for its storage. ${ }^{8}$ Moreover, $\mathrm{H}_{2} \mathrm{O}_{2}$ is commonly used in large scale reactions to synthesize caprolactam, $\left(\mathrm{CH}_{2}\right)_{5} \mathrm{C}(\mathrm{O}) \mathrm{NH}$ (Sumitomo Chemical Co. $)^{9}$ and in propylene oxidation (BASF and Dow Chemical Co.). ${ }^{10}$

Polyoxometalates are well known to act as catalysts for oxidation of olefins and alcohols with good selectivity. ${ }^{11}$ Due to the availability of dual oxidation states of metal ion, it offers the catalytic behaviour towards oxidation of alcohols and olefins resulting in aldehydes or ketones. Such properties are tuned by changing the counter cation of the polyoxoanions, for example, $\mathrm{Co}_{3}\left[\mathrm{Si}_{2} \mathrm{~W}_{12} \mathrm{O}_{40}\right]$ is a good catalyst in oxidation of alcohols, whereas, other salts of Keggin cluster anion, $\left[\mathrm{Si}_{2} \mathrm{~W}_{12} \mathrm{O}_{40}\right]^{6-}$ are not that much efficient catalyst for alcohol oxidation. ${ }^{12}$ In the present study, we have examined the catalytic applications of four polyoxometalate coordinated transition metal complexes, namely, $[2-\mathrm{ampH}]_{4}\left[\left\{\mathrm{Co}\left(\mathrm{H}_{2} \mathrm{O}\right)_{5}\right\} \mathrm{Mo}_{7} \mathrm{O}_{24}\right] \cdot 9 \mathrm{H}_{2} \mathrm{O} \quad(\mathbf{1})$, $[3-\mathrm{ampH}]_{4}\left[\left\{\mathrm{Co}\left(\mathrm{H}_{2} \mathrm{O}\right)_{5}\right\} \mathrm{Mo}_{7} \mathrm{O}_{24}\right] \cdot 9 \mathrm{H}_{2} \mathrm{O}(2),[2-\mathrm{ampH}]_{4}$ 
<smiles>C=Cc1ccccc1</smiles>

Styrene

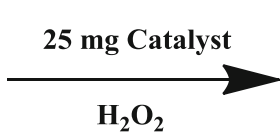

Benzaldehyde<smiles>O=Cc1ccccc1</smiles>

Benzoic acid

Scheme 1. Oxidation of styrene leading to benzaldehyde and benzoic acid using heptamolybdate coordinated transition metal complex as a catalyst.

$\left[\left\{\mathrm{Zn}\left(\mathrm{H}_{2} \mathrm{O}\right)_{5}\right\} \mathrm{Mo}_{7} \mathrm{O}_{24}\right] \cdot 4 \mathrm{H}_{2} \mathrm{O}(3)$ and $[3-\mathrm{ampH}]_{4}[\{\mathrm{Zn}(3-$ ampy) $\left.\left.\left(\mathrm{H}_{2} \mathrm{O}\right)_{4}\right\} \mathrm{Mo}_{7} \mathrm{O}_{24}\right] \cdot 4 \mathrm{H}_{2} \mathrm{O}$ (4) in the conversion of styrene to benzaldehyde/benzoic acid as shown in scheme 1. These catalysts are efficient to be reused for three times with similar percentage of conversion.

\section{Experimental}

\subsection{Materials}

[2-ampH $]_{4}\left[\left\{\mathrm{Co}\left(\mathrm{H}_{2} \mathrm{O}\right)_{5}\right\} \mathrm{Mo}_{7} \mathrm{O}_{24}\right] \cdot 9 \mathrm{H}_{2} \mathrm{O}(\mathbf{1}),[3-\mathrm{ampH}]_{4}$ $\left[\left\{\mathrm{Co}\left(\mathrm{H}_{2} \mathrm{O}\right)_{5}\right\} \mathrm{Mo}_{7} \mathrm{O}_{24}\right] \cdot 9 \mathrm{H}_{2} \mathrm{O}(2),[2-\mathrm{ampH}]_{4}\left[\left\{\mathrm{Zn}\left(\mathrm{H}_{2} \mathrm{O}\right)_{5}\right\}\right.$ $\left.\mathrm{Mo}_{7} \mathrm{O}_{24}\right] \cdot 4 \mathrm{H}_{2} \mathrm{O}(3)$ and $[3-\mathrm{ampH}]_{4}\left[\left\{\mathrm{Zn}(3-\mathrm{ampy})\left(\mathrm{H}_{2} \mathrm{O}\right)_{4}\right\}\right.$ $\left.\mathrm{Mo}_{7} \mathrm{O}_{24}\right] \cdot 4 \mathrm{H}_{2} \mathrm{O}(4)$ were synthesized according to literature procedures, reported by us and others. ${ }^{13}$ Styrene and $\mathrm{H}_{2} \mathrm{O}_{2}(30 \%)$ were purchased from Hi-Chem. Schematic representation for synthesis of four compounds 1-4 is shown in scheme 2 .

\subsection{Physical measurements}

Infrared (IR) spectra were recorded on $\mathrm{KBr}$ pellets with a JASCO FT/IR-5300 spectrometer in the region of $400-4000 \mathrm{~cm}^{-1}$. Electronic absorption spectra were recorded on a Cary 100 Bio UV-Vis spectrophotometer. G.C. analysis was performed on GCMS equipped with
ZB-1 column $(30 \mathrm{~m} \times 0.25 \mathrm{~mm}$, pressure $=20.0 \mathrm{k} \mathrm{Pa}$, detector $=\mathrm{EI}, 300^{\circ} \mathrm{C}$ ) with helium gas as carrier.

\section{Results and Discussions}

\subsection{Catalysis}

The oxidation of styrene with $30 \%$ of $\mathrm{H}_{2} \mathrm{O}_{2}$, catalyzed by four synthesized materials (compounds 1-4), produces benzaldehyde/benzoic acid as the major product; the minor products are styrene oxide and acetophenone. The advantages of these catalysts lie in the fact that they are recycled in the same oxidation for at least three times with similar percentage of conversion. The complete results of the styrene oxidation by using four catalysts are shown in table 1 . When the same oxidation was performed with ammonium heptamolybdate as a catalyst (instead of compounds 1-4: heptamolybdate cluster anion coordinated transition metal complexes), we found only $5 \%$ conversion. On the other hand, use of compounds 1-4 (as catalysts) results in a good percentage $(>95 \%)$ of conversion under similar condition. This demonstrates that, in the present study, transition metal complex, supported on the surface of POM cluster anion by coordinate-covalent bonds, acts as a catalyst. It is notable from table 1 that, isopolyanion
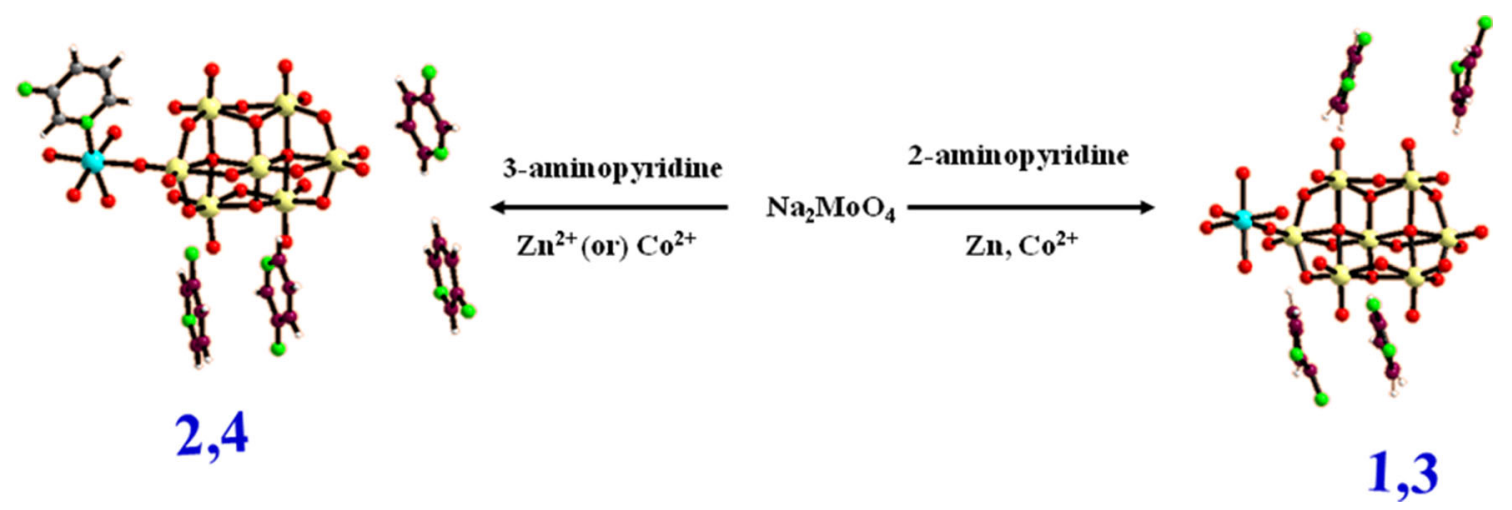

Scheme 2. Schematic representation for synthesis of compounds $[2-\mathrm{ampH}]_{4}\left[\left\{\mathrm{Co}\left(\mathrm{H}_{2} \mathrm{O}\right)_{5}\right\} \mathrm{Mo}_{7} \mathrm{O}_{24}\right] \cdot 9 \mathrm{H}_{2} \mathrm{O}$ (1), $[3-\mathrm{ampH}]_{4}\left[\left\{\mathrm{Co}\left(\mathrm{H}_{2} \mathrm{O}\right)_{5}\right\} \mathrm{Moo}_{7} \mathrm{O}_{24}\right] \cdot 9 \mathrm{H}_{2} \mathrm{O}(2),\left[2-\mathrm{ampH}_{4}\left[\left\{\mathrm{Zn}\left(\mathrm{H}_{2} \mathrm{O}\right)_{5}\right\} \mathrm{Mo}_{7} \mathrm{O}_{24}\right] \cdot 4 \mathrm{H}_{2} \mathrm{O}(3)\right.$ and $[3-\mathrm{ampH}]_{4}$ $\left[\left\{\mathrm{Zn}\left(3\right.\right.\right.$-ampy) $\left.\left.\left(\mathrm{H}_{2} \mathrm{O}\right)_{4}\right\} \mathrm{Mo}_{7} \mathrm{O}_{24}\right] \cdot 4 \mathrm{H}_{2} \mathrm{O}$ (4) (catalysts). Colour codes: Mo, yellow; $\mathrm{Co} / \mathrm{Zn}, \mathrm{Cyan} ; \mathrm{C}$, brown; $\mathrm{O}$, red; $\mathrm{N}$, green. 
Table 1. Oxidation of styrene by using the four catalysts (compounds 1-4 as catalysts).

\begin{tabular}{lcccccc}
\hline & & \multicolumn{5}{c}{ Selectivity (\%) } \\
\cline { 2 - 6 } Catalysts** & Conversion (\%) & Benzaldehyde & Epoxide & Benzyl alcohol & Benzoic acid & Acetophenone \\
\hline Compound $\mathbf{1}$ & 99.3 & 76 & - & - & 24 & - \\
Compound 2 & 96 & 76 & 3 & 5 & 15 & 1 \\
Compound 3 & 100 & 16 & - & 6 & 58 & 20 \\
Compound $\mathbf{4}$ & 100 & 15 & 3.8 & 1.2 & 69 & 11 \\
\hline
\end{tabular}

**A typical catalysis reaction includes $25 \mathrm{mg}$ of the catalyst, 1:2 ratio of styrene and $\mathrm{H}_{2} \mathrm{O}_{2}$ for catalysts $\mathbf{1}$ and 2 and 1:3 ratio of styrene and $\mathrm{H}_{2} \mathrm{O}_{2}$ for catalysts 3 and 4 , heating the reaction mixture at $80^{\circ} \mathrm{C}$ for $24 \mathrm{~h}$.

supported cobalt complexes (catalysts 1 and 2) produce benzaldehyde as maximum percentage of conversion, whereas, the isopolyanion supported zinc complexes (catalysts $\mathbf{3}$ and $\mathbf{4}$ ) bring about benzoic acid as the major product. The probable explanation for this diversity is the difference in stability of cobalt peroxide and zinc peroxide species, formed as intermediates during respective catalysis. ${ }^{14}$

The comparison of the IR spectrum of parent catalyst 1 with that of regenerated catalyst 1 suggests that compound $[2-\mathrm{ampH}]_{4}\left[\left\{\mathrm{Co}\left(\mathrm{H}_{2} \mathrm{O}\right)_{5}\right\} \mathrm{Mo}_{7} \mathrm{O}_{24}\right] \cdot 9 \mathrm{H}_{2} \mathrm{O}$ (1) remains identical even after several cycles of catalysis. Infrared spectra of both parent 1 and regenerated $\mathbf{1}$ are shown in the figures S1 and S2 respectively. Solid state (diffuse reflectance) electronic absorption spectra of the parent compound $\mathbf{1}$ and regenerated $\mathbf{1}$, shown in figures S3 and S4 respectively, also suggest that a catalyst does not leach during catalytic cycles. PowderXRD studies of parent compound $\mathbf{1}$ and regenerated $\mathbf{1}$ also indicate that a catalyst is not destroyed after the catalysis is over, as shown in figure S5. We have carried out the same reaction by a varying amount of hydrogen peroxide (oxidant) as well as by varying amount of the catalyst; the relevant observations have been described in tables 2 and 3 respectively.

As shown in table 2, increasing the concentration of $\mathrm{H}_{2} \mathrm{O}_{2}$ increases the percentage of conversion but the conversion of benzaldehyde is decreased. This is because the additional hydrogen peroxide oxidizes the generated benzaldehyde further to benzoic acid. So the conversion of benzoic acid increases with increase in concentration of $\mathrm{H}_{2} \mathrm{O}_{2}$. In all the cases, benzaldehyde is the product with major selectivity, especially under the condition of 1: 2 ratio of styrene and hydrogen peroxide; other products are epoxide and benzophenone with minor selectivity. We have run several reactions for styrene oxidation with catalyst $\mathbf{1}$ ([2-ampH $\left.]_{4}\left[\left\{\mathrm{Co}\left(\mathrm{H}_{2} \mathrm{O}\right)_{5}\right\} \mathrm{Mo}_{7} \mathrm{O}_{24}\right] \cdot 9 \mathrm{H}_{2} \mathrm{O}\right)$ under various conditions and finally a particular reaction condition was optimized with 1: 2 ratio of styrene and hydrogen peroxide at $80^{\circ} \mathrm{C}$ for $24 \mathrm{~h}$ for the maximum selectivity of benzaldehyde.

During catalysis, after 2 hours of reaction, the colour of the reaction mixture became yellow; subsequently this colour disappeared (after $10 \mathrm{~h}$ ) and finally the reaction mixture became bluish in colour. This may be due to the change in oxidation state of molybdenum in the reaction mixture. The catalyst is not soluble in any individual solvent (for example, in the starting substrates and in hydrogen peroxide separately) but it is completely soluble in reaction mixture (substrate + hydrogen peroxide). Thus the regeneration of the catalyst was done by evaporating the reaction mixture after separation of the organic part (extraction with DCM layer). The percentage of conversion increases with increasing the amount of the catalyst 1 (figure 1). Similarly, the selectivity of benzaldehyde increases with an increase in the amount of catalyst as shown in figure 1 . The identical trend was observed with a second catalyst for the same conversion.

Table 2. Results for the reaction of oxidation of styrene by varying the concentration of $\mathrm{H}_{2} \mathrm{O}_{2}$ (reaction condition is same as described in the caption of table 1).

\begin{tabular}{lcccccc}
\hline \multirow{2}{*}{$\begin{array}{l}\text { Reaction condition } \\
\left(\text { Sty: } \mathrm{H}_{2} \mathrm{O}_{2}\right)\end{array}$} & $\begin{array}{c}\text { Percentage } \\
\text { of Conversion }\end{array}$ & Benzaldehyde & Epoxide & Benzyl alcohol & Benzoic acid & Acetophenone \\
\hline $1: 1$ & 36 & 88 & 2 & - & 10 & - \\
$1: 2$ & 96 & 76 & - & - & 24 & - \\
$1: 3$ & 99.3 & 53 & 3.5 & - & 31 & 12.5 \\
\hline
\end{tabular}


Table 3. Results of percentages of conversion as a function of amount of catalyst $\mathbf{1}$ for the oxidation of styrene (reaction condition is same as described in the caption of table 1).

\begin{tabular}{lcccccc}
\hline \multirow{2}{*}{$\begin{array}{l}\text { Amount of } \\
\text { Catalyst } 1\end{array}$} & $\begin{array}{c}\text { Percentage of } \\
\text { Conversion }\end{array}$ & Benzaldehyde & Epoxide & Benzyl alcohol & Benzoic acid & Acetophenone \\
\hline $5 \mathrm{mg}$ & 74 & 56.6 & 3 & 4.4 & 28 & 8 \\
$10 \mathrm{mg}$ & 91 & 61.6 & 1 & 2 & 27 & 8.4 \\
$15 \mathrm{mg}$ & 98 & 65.4 & 4.6 & 3.8 & 18 & 8.2 \\
$20 \mathrm{mg}$ & 99 & 71 & 1.6 & 3.4 & 18 & 6 \\
$25 \mathrm{mg}$ & 99.6 & 76 & 0 & 0 & 24 & 0 \\
\hline
\end{tabular}
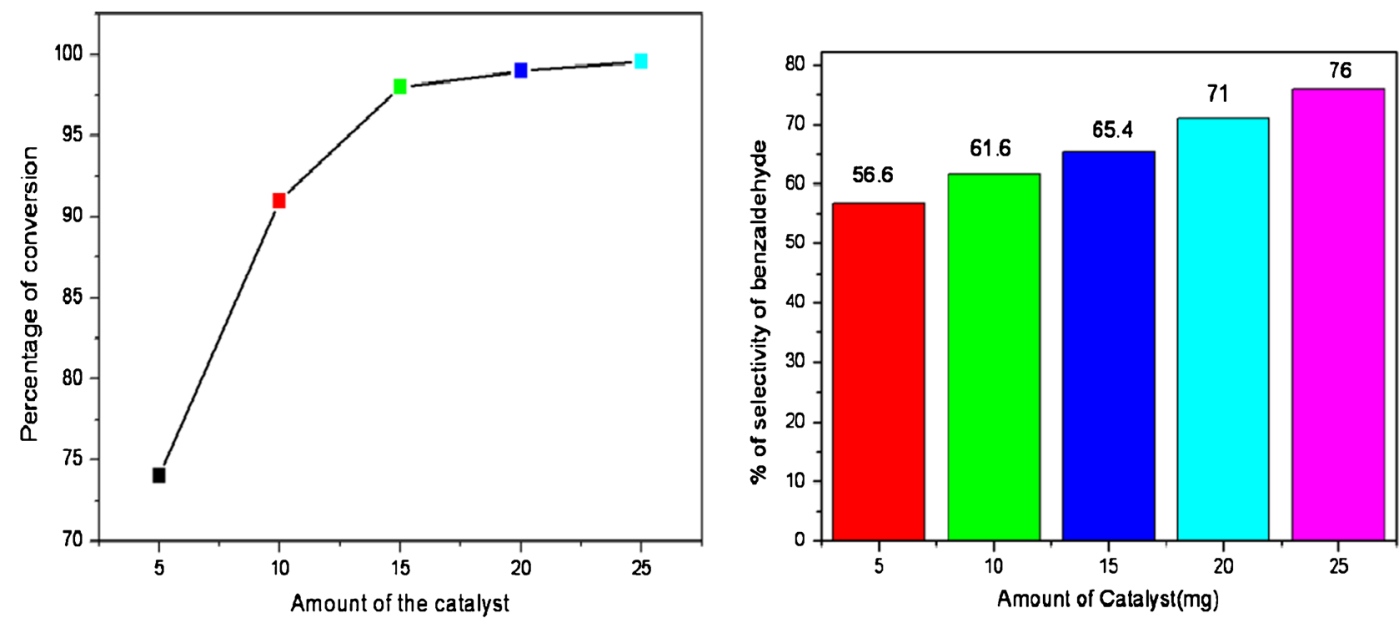

Figure 1. Left: graphical view of percentage of conversion in the reaction of oxidation of styrene with amount of catalyst. Right: selectivity $(\%)$ of benzaldehyde by changing the amount of catalyst 1.

\subsection{Leaching property of the catalyst}

All the catalysts (compounds 1-4) are regenerated by evaporation and reused for minimum of three times with similar percentage of conversion. Catalysts do not lose their catalytic activity until three times in the above said reaction, which has been established based on infrared spectroscopy, solid state UV spectroscopy and powder $\mathrm{X}$-ray crystallography as shown in the figures S1-S16 for catalysts 1-4.

\subsection{GC-MS calculations}

The oxidation of styrene is analyzed by gas chromatography-mass spectral studies. After completion of the reaction, DCM is added to the reaction mixture whereby the organic part comes to the DCM layer and the aqueous layer is evaporated to dryness to regenerate the catalyst. $0.8 \mu \mathrm{Lt}$. of the reaction mixture was injected into the column, from where it entered into the programmed oven (injector temperature: $200^{\circ} \mathrm{C}$ and detector temperature: $250^{\circ} \mathrm{C}$, ramping temperature: $\left.2.5^{\circ} \mathrm{C}\right)$.
The percentage-conversion of the substrate and the percentage-selectivity of the products in the reaction are calculated as shown below.

Percentage of conversion $=\{$ [initial $\mathrm{mol} \%$-final $\mathrm{mol} \%] /$ initial $\mathrm{mol} \%\} \times 100$.

Percentage of selectivity $=$ [product $\operatorname{mol} \% /$ substrate $\mathrm{mol} \%] \times 100$.

\section{Conclusion}

We have demonstrated the catalytic activity of four different heptamolybdate cluster coordinated/supported transition metal coordination complexes in the oxidation of styrene using $\mathrm{H}_{2} \mathrm{O}_{2}$ as an oxidant. All the catalysts have been reused for three cycles with similar yields. Benzaldehyde is produced as a major product with catalysts $\mathbf{1}$ and 2, whereas benzoic acid is the major product with catalysts $\mathbf{3}$ and $\mathbf{4}$. The leaching properties of the catalysts have been studied successfully and the relevant studies have been supported by infrared spectroscopy, solid state UV-visible spectroscopy and powder X-ray crystallography. 


\section{Supplementary Information}

FT-IR spectra, solid state UV spectra, powder Xray crystallographic data of parent catalysts and used/ regenerated catalysts (compounds 1-4) and the results for the reactions of styrene oxidation with catalysts 1-4 are available in supplementary information at www.ias. ac.in/chemsci.

\section{Acknowledgement}

We thank Science \& Engineering Research Board (a statutory body under the Department of Science and Technology), Government of India, for financial support (Project No. SB/SI/IC/034/2013). We also thank the Centre for Nano Technology, University of Hyderabad. The National X-ray Diffractometer facility at the University of Hyderabad by the Department of Science and Technology, Government of India, is gratefully acknowledged. ASR thanks CSIR, Government of India for a fellowship.

\section{References}

1. (a) Ben-Daniel R, Weiner L and Neumann R $1980 \mathrm{~J}$. Am. Chem.Soc. 124 8788; (b) Hayashi T, Kishida A and Mizuno N 2000 Chemm. Commun. 381; (c) Karcz R, Pamin K, Połtowicz J and Haber J 2009 Catal. Lett. 132 159; (d) Zhao W, Zhang B, Ma Y, Ding Y and Qiu W 2010 Catal. Commun. 11 527; Arumuganthan T, Rao A S, Kumar T V and Das S K 2008 J. Chem. Sci. 120 95

2. (a) Pope M T 2004 Compr. Coord. Chem. II 4 635; Hill C L 2004 Compr. Coord. Chem. II 4 679; (b) Pope M T and Müller A 1991 Angew. Chem., Int. Ed. 30 34; (c) Hill C L and Prosser-McCartha C M 1995 Coord. Chem. Rev. 143 407; (d) Hill C L 1998 Chem. Rev. 98 1; (e) Izumi Y, Urabe K and Onaka M 1992 In Zeolites, Clay and Heteropolyacid in Organic Reactions (Tokyo: Kodansha); (f) Khan M I, Yohannes E and Doedens R J 2003 Inorg. Chem. 42 3125; (g) Pope M T 1983 In Heteropoly and Isopoly Oxometalates (Berlin: SpringerVerlag)

3. (a) Yamase T 1993 Mol. Eng. 3 241; (b) Hill C L, Hartnup M, Faraj M, Weeks M, Prosser-McCartha C M,
Jr. R B B, Kadkhodayan M, Sommadossi J-P and Schinazi R F 1990 In Advances in Chemotherapy of AIDS, Pharmacology and Therapuetics R B Diasio and J -P Sommadossi (Eds.) (New York: Pergamon)

4. (a) Pappo R, Jr. D S A, Lemieux R U and Johnson W S J 1956 Org. Chem. 21 478; (b) Carlsen P H J, Katsuki T, Martin V S and Sharpless K B 1981 J. Org. Chem. 46 3936; (c) Michael B S 2002 Organic Synthesis $2^{\text {nd }}$ edition (New York: McGraw- Hill)

5. Bailey P S 1958 Chem. Rev. 58925

6. (a) Sheldon R A and Kochi J K 1981 In Metal-Catalyzed Oxidations of Organic Compounds (New York: Academic Press); (b) Sawyer D T 1991 In Oxygen Chemistry (New York: Oxford University Press)

7. (a) Jones C W 1999 In Applications of Hydrogen Peroxide and Derivatives (Cambridge: Royal Society of Chemistry); (b) Strukal G (ed.) 1992 In Catalytic Oxidations with Hydrogen Peroxide as Oxidant (Netherlands: Kluwer Academic)

8. For the international regulations, see: Regulations Concerning the International Carriage of Dangerous Goods by Rail (RID); European Agreement Concerning the International Carriage of Dangerous Goods by Road (ADR); International Maritime Dangerous Goods Code (IMDG Code); International Civil Aviation Organization Technical Instructions for the Safe Transport of Dangerous Goods by Air (ICAOTI); International Air Transport Association Dangerous Goods Regulation (IATA DGR)

9. Sumitomo Chemical News Release 2000 Oct. 11. Available at http://www.sumitomo-chem.co.jp/english/ e1newsrelease/pdf/20001011e.pdf

10. Dow Products and Businesses News 2002 Aug. 1. Available at http://www.dow.com/dow_news/prodbus/2002/ 20020801a.htm

11. (a) Noyori R, Aokib M and Sato K 2003 Chem. Commun. 1977; (b) Neumann R and Gara M 1995 J. Am. Chem. Soc. 117 5066; (c) Xinrong L, Jinyu X, Huizhang L, Bin Y, Songlin J and Gaoyanga X $2000 \mathrm{~J}$. Mol. Catal. A 161 163; (d) Patel K, Tripuramallu B K and Patel A 2011 Eur. J. Inorg. Chem. 1871; (e) Shringapuri P and Patel A 2010 Inorg. Chem. Acta. 362 3796; (f) Patel K, Shringarpuri P and Patel A 2011 Trans. Met. Chem. 36 171

12. Hill C L 1993 Mol. Eng. 3263

13. (a) Li T, Lü J, Gao S and Cao R 2008 Inorg. Chem. Commun. 10 1342; (b) Arumuganthan T, Rao A S and Das S K 2010 Cryst. Growth Des. 104272

14. Sebastian J, Jinka K M and Jasra R V 2006 J. Catal. 244 208 